\title{
L-carnitine in Hyperammonemia and Hepatic Encephalopathy
}

\author{
Jane Missler and Claudia Zwingmann \\ Centre de Recherche, de l'Université de Montréal (CHUM), Hôpital Saint-Luc \\ Montreal, Quebec, \\ Canada
}

\section{Introduction}

L-carnitine is suggested as a potential therapeutic agent in metabolic encephalopathies, such as ammonia-precipitated hepatic encephalopathy (HE). In humans, ammonia is produced mainly by the metabolism of proteins and amino acids. Most of the ammonia is detoxified by the urea cycle which is located in the liver. Thus, disturbances of the urea cycle in the liver lead to higher ammonia levels in blood. In humans, hyperammonemia (HA) arises mainly from liver diseases and is in most cases associated with HE. There are currently only a few therapeutic strategies, and outcome expectations for patients with HE are poor. Lcarnitine and its acyl-derivates are suggested as potential and low-cost therapeutic agents. In animal models, L-carnitine has been shown to counteract neurotoxic effects of ammonia, increase energy metabolism and decrease mortality. A protective effect against ammoniaprecipitated HE has also been observed in cirrhotic patients. A review of the literature offers in vitro and in vivo studies, as well as human trials with promising results. This chapter provides a comprehensive summary and a summarized discussion of the literature data concerning the effects of L-carnitine, with special emphasis on hyperammonemic syndromes and HE.

L-carnitine is essential for the transfer of long-chain fatty acids from the cytoplasm to the inner mitochondrial membrane, thereby facilitating mitochondrial energy metabolism. By virtue of their metabolic functions and neurophysiological roles, L-carnitine and its acetylated derivates are suggested as a therapeutic agent in several neurological disorders, including HE. In the brain, they have important roles in cerebral bioenergetics and neuroprotection through a variety of mechanisms including their antioxidant properties by modulation and promotion of synaptic neurotransmission. However, questions remain as to its systemic vs. cerebral effects, its relative effects on astrocytes and neurons, and its clinical use.

High-resolution Nuclear Magnetic Resonance (NMR) approaches using stable isotopes are now yielding large amounts of detailed information on cerebral metabolic compartmentalization and neuronal-glia interactions (Zwingmann \& Leibfritz, 2003). In order to investigate the effect of L-carnitine on energy- and fatty acid metabolism, ${ }^{1} \mathrm{H}$ - and ${ }^{13} \mathrm{C}-\mathrm{NMR}$ spectroscopy was used to measure metabolic pathways in brain and muscle 
following administration of [U-13C]glucose to rats with mild $\mathrm{HE}$ and in rats with ammoniaprecipitated encephalopathy. As a model of mild HE, we investigated rats four weeks after an end-to-side portacaval anastomosis (PCA). PCA in the rat resulted in a broad spectrum of neurobehavioral changes, such as an $80 \%$ impaired locomotor activity, which was largely prevented by L-carnitine. Concomitantly, L-carnitine improved mitochondrial energy metabolism in brain and muscle. In ammonia-precipitated encephalopathy, L-carnitine considerably delayed the rats' time to coma, concomitantly with a prevention of ammoniainduced increased lactate synthesis in the brain. These results demonstrate that in HE, Lcarnitine acts both in the brain and in the muscle not by improving ammonia removal but by improving mitochondrial metabolism. These mechanisms explain L-carnitine's therapeutic benefit in the prevention of mild HE and ammonia-precipitated encephalopathy in cirrhotic patients. Since it is a low-cost agent with few side effects, further clinical trials could be promising in evaluating the broader use of L-carnitine and derivatives in patients with HE.

\section{Hyperammonemia}

The gut bacterial flora are responsible for the production of ammonia, the end-product of bacterial protein metabolism. The proteins that are metabolized by bacteria originate from exogenous alimentary sources (e.g. meat) or from endogenous sources (e.g. gastro-intestinal hemorrhage) (Hoyumpa et al., 1979). After ammonia is generated, ammonia can be detoxified by the formation of amino acids in the liver or in extrahepatic organs. One important mechanism is the synthesis of glutamine from glutamate and ammonia in the muscle (Fig. 1). The glutamine derived from muscle can be used as an energy substrate in the gut and is also transported to the kidney, where it is hydrolyzed to glutamate and ammonia. In the kidney, ammonia is detoxified by urea synthesis, which is released by the urine. Portal vein ammonia is present at a very high concentration. It is transported through the portal circulation to the liver, where it is normally converted to urea through the urea cycle and subsequently released by the kidney (McDermott, 1957). In liver diseases, the normal ammonia detoxification mechanisms may be compromised, and excess ammonia enters the brain. Furthermore, as it can occur in chronic cirrhosis or construction of a portacaval shunt, the shunting of the blood passing the liver will greatly increase systemic ammonia concentrations, which may then enter the central nervous system (CNS) (Butterworth et al., 1987; Lockwood et al., 1979). Since the brain lacks an effective urea cycle, basically the only mechanism to detoxify ammonia is conversion to glutamine through glutamine synthetase (GS). In the CNS, GS is localized almost exclusively in the astrocytes (Norenberg \& Martinez-Hernandez, 1979).

The metabolic conversion system that leads to the production of urea is highly efficient, and under healthy conditions it is unlikely to become hyperammonemic. $\mathrm{HA}$ is not a true disease; it is a sign that specific abnormalities, e.g. urea cycle disorders and liver diseases, that cause blood ammonia levels to become elevated may be present.

HA is considered a key factor in HE, which is defined as a spectrum of neuropsychiatric abnormalities in patients with liver dysfunction, after other known brain disease has been ruled out. In the brain, high ammonia levels modify several amino acid pathways and neurotransmitter systems, as well as cerebral energy metabolism, nitric oxide synthesis, antioxidant systems, mitochondrial permeability transition and signal transduction 
pathways. HE due to both chronic liver failure (CLF) and acute liver failure (ALF) is manifested by neuropathological changes that primarily affect astrocytes. The main pathological manifestation in CLF and chronic HA is the appearance of Alzheimer type II astrocytosis (Norenberg, 1977, 1987). In HA and HE due to ALF, death most frequently results from brainstem herniation due to increased intracranial pressure as a result of a progressive increase of brain water content (brain edema) due to astrocyte swelling (Blei, 2001; Butterworth, 1998; Chung et al., 2001; Cordoba \& Blei, 1995; Larsen et al., 2001). Among other mechanisms, ammonia-induced disturbances in the synthesis and degradation of the neuronal neurotransmitter amino acid glutamate lead to changes in its brain levels as well as in its reuptake by astrocytes (Butterworth, 2002; Michalak et al., 1996). The resulting excitotoxic levels in the cerebrospinal fluids (CSF) can lead to an overactivation of glutamatergic receptors on the postsynaptic neuron.

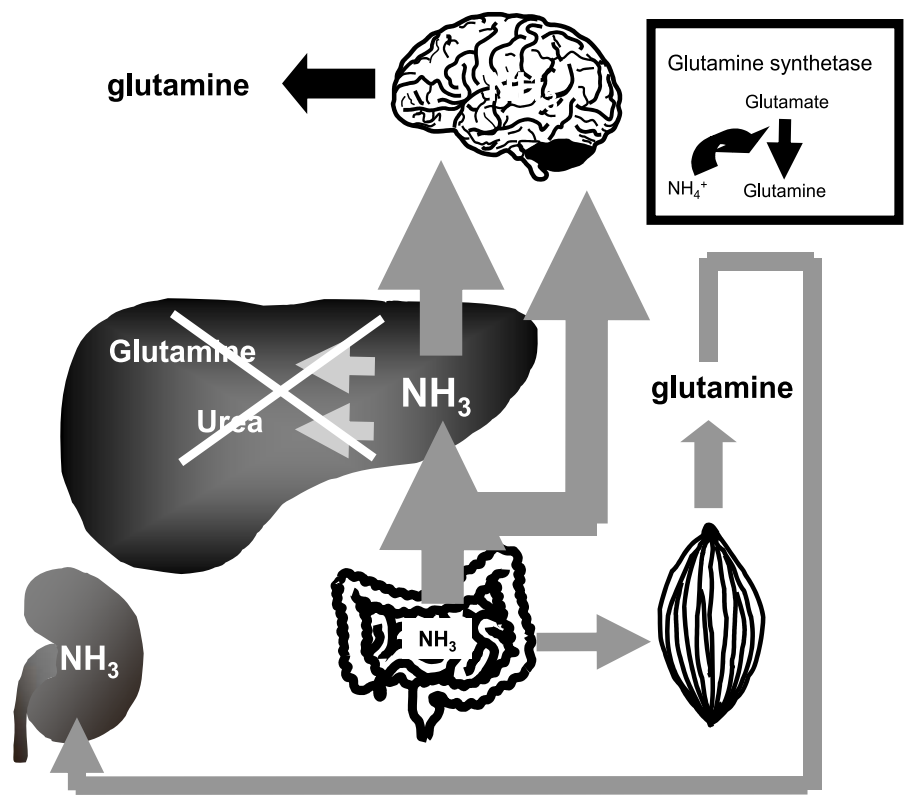

Fig. 1. Development of hyperammonemia. The production of ammonia in the gastrointestinal tract occurs as a result of the action of bacteria on nitrogenous substances, as well as gastrointestinal bleeding. After ammonia is generated, the principal fate is incorporation into glutamine in extrahepatic organs, such as the muscle. The glutamine derived from muscle acts as an energy source for the gut and at the same time releases ammonia for urea synthesis in the kidney. Portal vein ammonia, on the other hand, which is present at a much higher concentration, is largely detoxified as urea in the liver and released by the kidney. When the liver fails due to dysfunction or shunting of the portal venous blood, large amounts of ammonia enter the brain. Basically the only way to detoxify ammonia in the brain is by synthesis of glutamine. 
The neuronal N-methyl-D-aspartate (NMDA) receptor is a glutamatergic ionotropic receptor, and elevated ammonia levels lead to an excessive activation of this receptor (Cauli et al., 2008; Monfort et al., 2002). This induces an increased expression of the neuronal nitric oxide synthase (nNOS) producing nitric oxide (NO). NO reduces the activity of antioxidant enzymes, leading to increased formation of superoxides and therefore to oxidative stress (Kosenko et al., 1998, 1999). NO can also interact with superoxide anions to form peroxynitrite, which is a powerful nitration reagent. It nitrates tyrosine residues in proteins, including enzymes such as GS (Rose \& Felipo, 2005), resulting in an inhibition of their activity. Another consequence of oxidative stress is the activation of mitogen-activated protein kinases (MAPKs). The kinases are key substances of intracellular signaling cascades, which control a number of cellular responses to extracellular impulses. Increased ammonia levels lead to phosphorylation of these enzymes, and recent studies suggest the involvement of MAPK phosphorylation in the mechanisms of ammonia-induced astrocyte dysfunction and cell swelling (Jayakumar et al., 2006).

The energy metabolism of the CNS is affected by ammonia in different ways. Increased ammonia levels have been suggested to inhibit the tricarboxylic acid (TCA) cycle enzyme aketoglutarate dehydrogenase (Lai \& Cooper, 1986). More recently, a direct effect of ammonia on neuronal pyruvate dehydrogenase (PDH) has been proposed by NMR studies (Chatauret et al, 2003; Zwingmann et al., 2003). PDH is a mitochondrial matrix multienzyme complex that provides the link between glycolysis and the TCA cycle by catalyzing the conversion of pyruvate into acetyl-CoA. If $\mathrm{PDH}$, and subsequently mitochondrial energy production, is compromised, a switch to glycolysis may in part compensate by cytosolic ATP production. As a result, and to maintain reduced equivalents needed for glycolytic conversion of glucose, lactate dehydrogenase $(\mathrm{LDH})$ converts pyruvate to lactate which accumulates (Kala \& Hertz, 2005; Zwingmann et al., 2003, 2007; Zwingmann \& Butterworth, 2005). On the other hand, the stimulation of the glycolytic enzyme phosphofructokinase by ammonia (Ratnakumari \& Murthy, 1993) also leads to elevated lactate levels. Consistent with these possibilities, brain lactate concentrations have been consistently found to be increased in brain and extracellular fluid of various animal models of acute HA (Bates et al., 1989; Deutz et al., 1988; Holmin et al., 1983; Michalak et al., 1996; Peeling et al., 1993), as well as in patients with ALF (Tofteng \& Larsen, 2002). Previous studies have shown that, like ammonia, lactate exposure to cultured astrocytes also results in significant cell swelling (Staub et al., 1990).

While ammonia may impair mitochondrial glucose oxidation, some of the neuropathological manifestations in hyperammonemic states in liver failure may be mediated by the accumulation of astrocytic glutamine as a result of ammonia detoxification (Norenberg et al., 2007). While the osmotic effect of glutamine might not be the primary cause of astrocyte swelling, its accumulation has been shown to have secondary effects on astrocyte function, energy metabolism and neurotransmitter homeostasis. For example, glutamine, as well as ammonia itself, can induce the mitochondrial permeability transition (Rama Rao et al., 2003). The increased permeability can lead to elevated levels of osmolytes in the astrocytes and subsequent to a collapse of the mitochondrial inner membrane potential, resulting in mitochondrial dysfunction and enhanced free radical production (Norenberg et al., 2007). Increased levels of both glutamine and lactate, as well as changes in membrane permeability, can contribute to an enhanced water influx into the astrocytes and 
thereby to swelling of the cells (Bachmann, 2002; Chatauret et al., 2003; Norenberg et al., 1998; Rama Rao et al., 2003). Specifically in acute disease states, astrocyte swelling is a major cause of cerebral edema and intracranial hypertension, leading to encephalopathy, coma and death.

\section{Hepatic encephalopathy}

HE is a clinical manifestation due to CLF or ALF. HE is classified according to the West Haven Criteria. These define HE grade I to IV, based on the presence of specific clinical signs and symptoms and their intenseness (Ferenci et al., 1998). Manifest encephalopathy is characterized by neuropsychiatric symptoms ranging from mild personality changes and impairment of consciousness, attention span and orientation (grade I) to deep coma (grade IV). It is diagnosed by clinical signs, neuropsychiatric evaluations and neuroimaging methods. Patients with minimal HE show no significant symptoms of brain dysfunction, but it can have a far-reaching impact on quality of life, ability to function in daily life and progression to overt hepatic encephalopathy. For example, many patients with minimal HE show an impaired ability to drive a motor vehicle (Wein et al., 2004). The diagnosis of minimal HE is primarily carried out by the flicker test (Kircheis et al., 2002a). The critical flicker frequency (CFF) analysis is an objective and reproducible assay of HE severity. It defines the frequency at which light pulses are perceived as fused or flickering light. The technique shows little dependence upon age, education or training and is even able to detect minimal encephalopathy.

HA is considered to be a key factor in both forms of liver failure, but its relation to neurological damage in HE is poorly understood. Furthermore, there are other precipitating factors in $\mathrm{HE}$, such as elevated manganese, hyponatraemia, inflammatory cytokines and benzodiazepine-type sedatives (Cordoba \& Minguez, 2008; Haeussinger \& Schliess, 2008). HE occurs mostly as a result of a chronic disease. The current epidemic of hepatitis $\mathrm{C}$, for example, emphasizes the importance of this clinical problem, particularly with regard to the extremely high mortality rate of $80-90 \%$ (Schiodt et al., 1999). However, HE development also appears acutely in previously healthy individuals due to viral hepatitis or overexposure to hepatotoxins like acetaminophen. While the chronic form of HE progresses slowly, rapid deterioration in consciousness level and death usually occur in the acute form of HE.

\subsection{Therapeutic means in Hepatic encephalopathy}

There are different therapeutic means of treating patients with HE. One possibility is a liver support device and liver transplantation, a definitive therapeutic strategy that improves outcomes in patients. However, there are several drugs being examined in research and clinical trials that could benefit patients with HE. Most of them tend to reduce the production and absorption of ammonia from the colon (Bass, 2007; Morgan et al., 2007). Furthermore, non-absorbable disaccharides inhibit bacterial ammonia production in the colon and retard ammonia as non-diffusable ammonium in the intestinal colon (Cammà et al., 1993). But in many cases, studies approving the efficacy and safety of the drugs are limited (Bass, 2007). Antibiotics are administered to reduce the quantity of enteric bacteria which produce ammonia. For example, rifaximin seems to be more effective than other antibiotics and is inexpensive (Leevy \& Phillips, 2007). 
Also, substances modifying ammonia metabolism are considered as therapeutic means in HE. Commonly used pharmacologic agents to treat HA are sodium phenylacetate and sodium benzoate, which can serve as alternatives to urea for nitrogen excretion. Phenylacetate conjugates with glutamine, a major detoxification product of ammonia, to form phenylacetylglutamine, which is excreted by the kidney. Sodium benzoate, on the other hand, reduces ammonia levels in blood because it is metabolized to hippurate by conjugation with glycine, which is rapidly excreted by the kidney (Morgan et al., 2007).

A primary liver function is the regulation of amino acid supply to peripheral tissues. In HE, an increase of aromatic amino acids compared to branched-chain amino acids has been observed, which could be modified by the intake of branched-chain amino acids (Bass, 2007). Also L-Ornithine-L-Aspartate lowers ammonia levels in blood as it provides substrates for the metabolic conversion of ammonia to urea and glutamine (Kircheis et al., $2002 \mathrm{~b}$ ). Another means of treating HA is restriction of dietary protein (a source of ammonia), while caloric intake is provided by glucose and fat. Less investigated to date are L-carnitine and its derivatives, which are suggested to increase fat metabolism and have been suggested to decrease ammonia concentrations in blood by raising metabolic energy production (Bass, 2007).

\section{L-carnitine}

L-carnitine (L-4-N-trimethylammonium-3-hydroxybutyric acid) is known to be involved in long-chain fatty acid metabolism. The quatenary amine is synthesized in the liver and kidney from lysine and methionine (Bremer, 1983; Steiber et al., 2004). However, the major part of the daily requirement is covered by dietary intake. For example, food of animal origin, particularly red meat, contains significant amounts of L-carnitine (Steiber et al., 2004).

L-carnitine is essential for the transfer of long-chain fatty acids from the cytoplasm to the inner mitochondrial membrane for their oxidation (Fig. 2). Fatty acids are released from adipose tissue into the plasma. There, they are bound to albumin and carried to muscles, where a membrane transporter yields them into the cytoplasm. In the cytoplasm the fatty acids are activated by conjugation to Coenzyme A by means of Coenzyme A synthase. The acyl group from acyl-CoA is then transferred to the inner aspect of the outer mitochondrial membrane via the L-carnitne palmitoyl transferase I (CPTI) where it is linked to L-carnitine. The acylcarnitine is subsequently translocated across the inner mitochondrial membrane by the carnitine-acylcarnitine translocase (CACT). In the mitochondrial matrix acylcarnitine is reconverted to acyl-CoA and L-carnitine through carnitine palmitoyl transferase II (CPTII). The released L-carnitine is returned to the cytoplasm via carnitine palmitoyltransferase II, while the acyl-CoA can be metabolized through $\beta$-oxidation to acetyl-CoA (Bremer, 1983; Luppa, 2004; Virmani \& Binienda, 2004). The $\beta$-oxidation of fatty acids is important because it provides acetyl-CoA, a substrate for the TCA cycle. Thus, decreased intramitochondrial transport of fatty acids due to carnitine deficieny can lead to an inhibition of mitochondrial pyruvate oxidation in the TCA cycle. Since the reaction of the carnitine palmitoyl transferase is reversible, it is possible to release acetylcarnitine from the mitochondria into the plasma. Therefore, L-carnitine acts as a buffer for the acetyl-CoA/CoASH ratio (Luppa, 2004; Steiber et al., 2004) and activates the mitochondrial respiration rate. 
acyl-CoA + carnitine
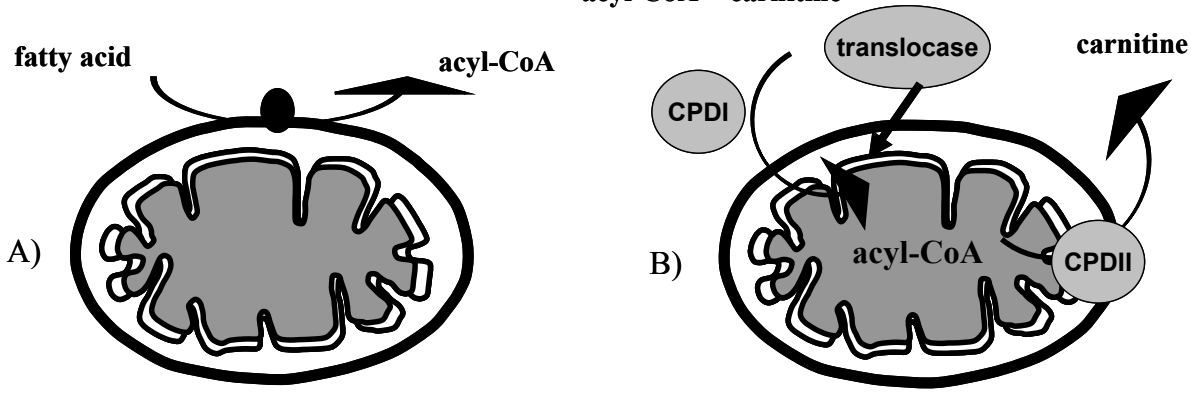

Fig. 2. Suggested action of L-carnitine. L-carnitine can facilitate the entry of fatty acids into the mitochondria. These fatty acids can be used to produce energy. A) Fatty acids must first be activated in the outer mitochondrial membrane before they can be used. Acetyl-CoA synthetase activates the fatty acid and transforms it to acyl-CoA. B) Activated fatty acids in the form of acyl-CoA are carried across the mitochondrial membrane by L-carnitine. L-carnitine is recycled back. In the mitochondria, acyl-CoA undergoes $\beta$-oxidation to produce acetyl-CoA, which is used for mitochondrial energy production in the TCA cycle.

\subsection{L-cartinine in the CNS}

Tissue that copes with its energy demands by fatty acid oxidation, i.e. liver, muscles, kidney and heart, contains high levels of L-carnitine. Significant amounts of L-carnitine are also localized in the brain. Although the main energy production in the brain occurs by mitochondrial glucose oxidation, it has been observed that at least part of the cerebral energy production from acetyl-CoA occurs via fatty acid oxidation, most notably in astrocytes (Ebert et al., 2003). Another major task of L-carnitine in the brain is the transfer of acetyl-CoA from the mitochondria into the cytoplasm (see above). By this means acetyl-CoA also provides acetyl groups for the synthesis of the neurotransmitter acetylcholine. In addition, L-carnitine and its acylderivates can change the activity of certain proteins such as cysteine aspartic acid specific proteases (caspases) (Mutomba et al., 2000). They are also able to modify membrane fluidity and surface charge and therefore alter the activity of several enzymes and transporters that are located in the membrane (Nałecz et al., 2004; Virmani \& Binienda, 2004). L-carnitine and its acylderivates may also increase the synthesis of phospholipids, which are required for membrane formation and integrity, and thereby modulate neuronal activity (Virmani \& Binienda, 2004).

There are two known forms of L-carnitine deficiency, the primary systemic and the secondary deficiency. Primary systemic L-carnitine deficiency is caused by several defects in the biosynthesis and transport of L-carnitine. This leads to increased excretion of L-carnitine and decreased L-carnitine accumulation in tissues (Longo et al., 2006, Vielhaber et al., 2004). Secondary L-carnitine deficiency occurs due to genetically defined disturbances in fatty acid oxidation and amino acid homeostasis. Several medical conditions, such as cirrhosis and other metabolic disorders, lead to secondary L-carnitine deficiency, as well as hemodialysis or kidney failure (Fornasini et al., 2007, Virmani \& Binienda, 2004). Both disorders induce the same symptoms, like periodic encephalopathies which often come along with 
hypoglycemia and hypoketonia. Other symptoms are hypotonia, weakness, episodes of coma, seizures, neuropathy and anemia.

\subsubsection{Pharmaceutical use of L-carnitine in brain disorders}

By virtue of their metabolic functions and neurophysiological roles, L-carnitine and its acetylated derivates are suggested as a therapeutic agent in several neurological disorders. Among others, the effects of L-carnitine and its derivates have been investigated in Alzheimer's disease, chronic fatigue syndrome, Parkinson's disease, and neuropathic pain, as well as in valproic acid intoxication associated with CNS depression and raised ammonia levels without hepatotoxicity (Beal, 2003; Chan et al., 2007; Kuratsune et al., 2002; Pittler 7 Ernst, 2008; Silva et al., 2008). Fatty acid metabolism plays a major role in brain energy metabolism since acetyl-CoA enters the mitochondrial TCA cycle via PDH in both astrocytes and neurons (Fig. 3).

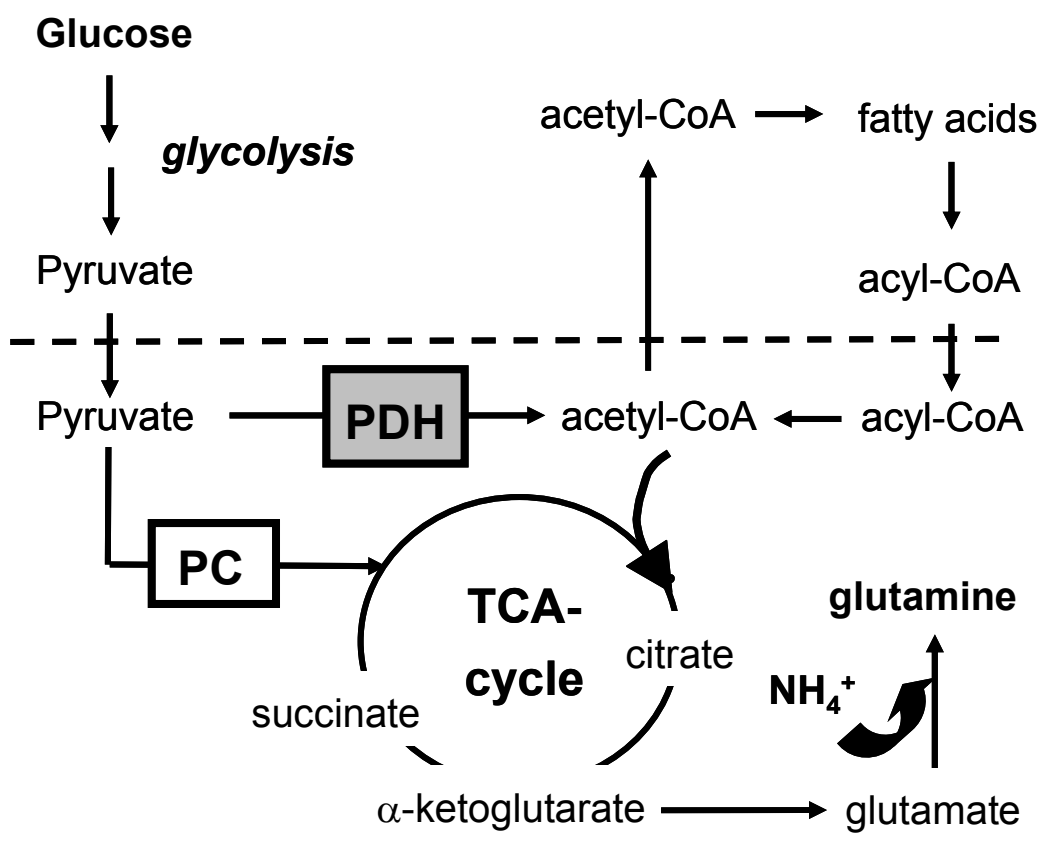

Fig. 3. Formation of acetyl-CoA from glucose and fatty acids. Glycolysis transforms glucose into pyruvate. Pyruvate may enter the TCA cycle via the anaplerotic pathway (PC; EC 6.4.1.1) or the oxidative pathway (PDH; EC 1.2.4.1) through acetyl-CoA. Acetyl-Coa can also be formed from fatty acids after the entry of acyl-CoA from the cytosol into the mitochondria, a process which is facilitated by L-carnitine.

In cerebral diseases, where mitochondrial dysfunction, impaired energy metabolism and oxidative stress play a decisive role for their development, such as in Parkinson' s disease, Lcarnitine has been shown to improve overall metabolic activity by yet unknown mechanism 
(Beal, 2003, Zhang et al., 2008). Also, in vitro models have shown significant improvements of mitochondrial biogenesis when L-carnitine is given in combination with other mitochondrial nutrients, such as R-a-Lipoic acid (Zhang et al., 2008).

In the brain, both L-carnitine and acetyl-L-carnitine play further important roles in cerebral bioenergetics and neuroprotection through a variety of mechanisms, including their antioxidant properties through the modulation and promotion of synaptic neurotransmission (Inazu \& Matsumiya, 2008). Alzheimer's disease and chronic fatigue syndrome occur mainly in the elderly. L-carnitine and its derivates can restore changes in membrane phospholipid metabolism found in subjects with Alzheimer's disease (Montgomery et al., 2003; Pettegrew et al., 2000). Furthermore, it is able to enhance quality of life in patients with Alzheimer's disease and chronic fatigue syndrome because of its cholinergic function and stimulation of cellular energy production (Malaguarnera et al., 2007, 2008; Pettegrew et al., 2000). Acetyl-L-carnitine has also been successfully applied as a pharmacological agent for the treatment of chronic degenerative diseases of the senile brain and for slowing down the progression of mental deterioration in Alzheimer's disease. The mechanisms may involve both the cholinergic neuronal transmission activity of acetyl-Lcarnitine and its ability to enhance neuronal metabolism in mitochondria (Inazu \& Matsumiya, 2008). Neuropathic pain has several causes, such as diabetes polyneuropathy, HIV, or chemotherapeutic agents. In these cases, acetyl-L-carnitine has been shown to have an analgesic effect due to its cholinergic action. Moreover, it is able to improve nerve function by activating several receptors via acetylation (Chiecho et al., 2007, Sima, 2007). Valproic acid is a broad-spectrum antiepileptic drug which is known to reduce L-carnitine level, and can lead to HA. It has been suggested that L-carnitine may decrease ammonia levels by binding to valproic acid (Chan et al., 2007, Lheureux et al., 2005, Wadzinski et al., 2007).

\subsubsection{L-carnitine in experimental hyperammonemia}

HA can be induced in animal models by several approaches. Major common methods are to inject neurotoxic amounts of ammonium acetate or to feed the animals a high ammonia diet. Several studies have demonstrated that L-carnitine can prevent acute ammonia toxicity and decrease its effects on the brain. O'Connor et al. (1984 a, 1984 b) injected L-carnitine in mice $30 \mathrm{~min}$ before administration of a lethal dose of ammonia acetate. They demonstrated that Lcarnitine reduces mortality (100\% survival with $12 \mathrm{mmol} / \mathrm{kg}$ body weight) and prevents symptoms of ammonia toxicity. Survival and beneficial effects depended on the dose of Lcarnitine. From these data, it was suggested that the protective effect of L-carnitine is based on significant improvements in the cellular redox state and mitochondrial energy metabolism. The concomitant decrease in blood and brain ammonia concentrations was proposed to be due to activation of the urea cycle by L-carnitine via carbamyl phosphate synthetase. I Matsuoka \& Igisu (1993a) compared the effects of L-carnitine, D-carnitine and acetyl-L-carnitine in the therapy of acute HA in mice. Marked alterations were observed in brain energy metabolites after ammonia injection, which were suppressed by all three substances together with reduced blood and brain ammonia levels and a reduction in the frequency of seizures. Interestingly, acetyl-L-carnitine better conserved adenonsinetriphosphate (ATP) in the brain, while it reduced ammonia levels in the blood and brain less markedly. These results suggest that the protective actions of L-carnitine and its derivates are systemic, and that the effect of acetyl-L-carnitine differs from that of L-carnitine. In a 
previous study, the authors injected mice with sublethal doses of ammonium acetate to rule out the effects of seizures on brain energy metabolism (Matsuoka and Igisu, 1993b). These data further showed that L-carnitine improves brain energy metabolism in experimental HA in a systemic manner and not by suppression of seizures. Another study investigated the effects of different L-carnitine doses on cerebral and hepatic energy metabolites in hyperammonemic sparse-fur (spf) mutant mice with X-linked ornithine transcarbamylase deficiency, a model of congenital chronic HA. It was shown that L-carnitine is able to activate the fatty acid oxidation during sodium benzoate treatment (Ratnakumari et al., 1993b). Sodium benzoate reduces ammonia levels through hippurate formation. A possible side effect is decreased levels of acetyl-CoA due to formation of benzoyl-CoA, while Lcarnitine was able to restore the availability of free CoA and thereby could reduce ammonia levels and improve energy metabolism. Subsequently, Ratnakumari et al. (1995) studied the effect of acetyl-L-carnitine on the development of cerebral cholinergic parameters in the same mouse model of HA. Cholinergic deficiency in hyperammonemic mice was significantly improved by treatment with acetyl-L-carnitine. The reason for the restoration could be an L-carnitine induced elevation of nerve growth factor levels and activation of choline acetyltransferase (Ratnakumari et al., 1995). In the study by Rao and Qureshi (1999), HA led to an excessive release of glutamate, which in turn resulted in upregulation of the NMDA receptor. The cellular reuptake of glutamate depends on sufficient availability of ATP levels. The results of this study demonstrated that acetyl-L-carnitine modulates the binding sites of the NMDA receptor, while enhanced ATP production via the TCA cycle, activated by acetyl-L-carnitine, might have contributed to stimulated uptake of glutamate from the extracellular fluid.

A model of ammonia-precipitated encephalopathy is the portacaval-shunted rat receiving ammonium acetate (Belanger and Butterworth, 2005). In this model, Therrien et al. (1997) examined the effect of L-carnitine $(16 \mathrm{mmol} / \mathrm{kg}$, intraperitoneally), given 1 hour before ammonium acetate $(8.5 \mathrm{mmol} / \mathrm{kg}$, subcutaneously) to portacaval shunted rats. Hyperammonemic rats manifested severe encephalopathy progressing through loss of righting reflex to coma, and the survival rate was $5 \%$. Similar to the study by O'Connor et al. (1984), none of the L-carnitine treated animals died or showed neurological impairments. However, L-carnitine pretreatment did not substantially reduce plasma ammonia levels or increase CSF or brain glutamine levels in these rats, while it reduced CSF ammonia. Interestingly, L-carnitine reduced ammonia-induced increases in CSF lactate and alanine, suggesting an improvement of cerebral mitochondrial energy metabolism. According to the studies mentioned above, L-carnitine exerts protective effects against cerebral energy distortions and neuronal dysfunction in HE.

\subsection{L-carnitine in in vitro ammonia toxicity}

In addition to experimental animals with HA, studies were performed in hippocampal slices and cultured neurons to evaluate some mechanistic aspects of the effect of L-carnitine. Many of the cerebral effects of ammonia have been explained by extracellular glutamate accumulation and NMDA receptor activation by both ammonia or glutamate. In primary neurons, for example, it has been demonstrated that L-carnitine prevented glutamate neurotoxicity in a dose-dependent manner similar to that required to prevent ammonia toxicity in animals, and decreased the affinity of glutamate for the NMDA receptor (Felipo et al., 1994). In a study by Llansola et al. (2002), treatment of primary neurons in culture with 
$1 \mathrm{~m} M$ glutamate caused cell death of $80 \%$. In this system glutamate neurotoxicity was mainly mediated by activation of NMDA receptors. The addition of $1 \mathrm{mM}$ L-carnitine 15 min before glutamate prevented neuronal death caused by glutamate. Furthermore, Lcarnitine increased the binding affinity of glutamate for metabotropic glutamate receptors, which was reversed if metabotropic glutamate receptors were blocked with specific antagonists (Llansola et al., 2002). Further studies in primary cultured neurons also indicated that L-carnitine interferes with NMDA-induced, NO mediated activation of MAP kinase at a step subsequent to NO formation (Llansola \& Felipo, 2002). However, as mentioned above, recent studies suggest that MAPK phosphorylation is also involved in the mechanisms of ammonia-induced astrocyte dysfunction and cell swelling (Jayakumar et al., 2006). In rat hippocampal slices, L-carnitine was able to reverse some of the inhibitory effects of ammonia on respiratory energy metabolism and mitochondrial function (Izumi et al., 2005). In these studies, mitochondrial function was measured using a mitochondrial dehydrogenase assay (Fig. 4). Incubation of the slices with $1 \mathrm{mM}$ ammonia significantly reduced the production of the formazan end product. This reduction in enzymatic activity was overcome by co-administration of $1 \mathrm{mM}$ L-carnitine, while L-carnitine itself did not facilitate formazane formation.

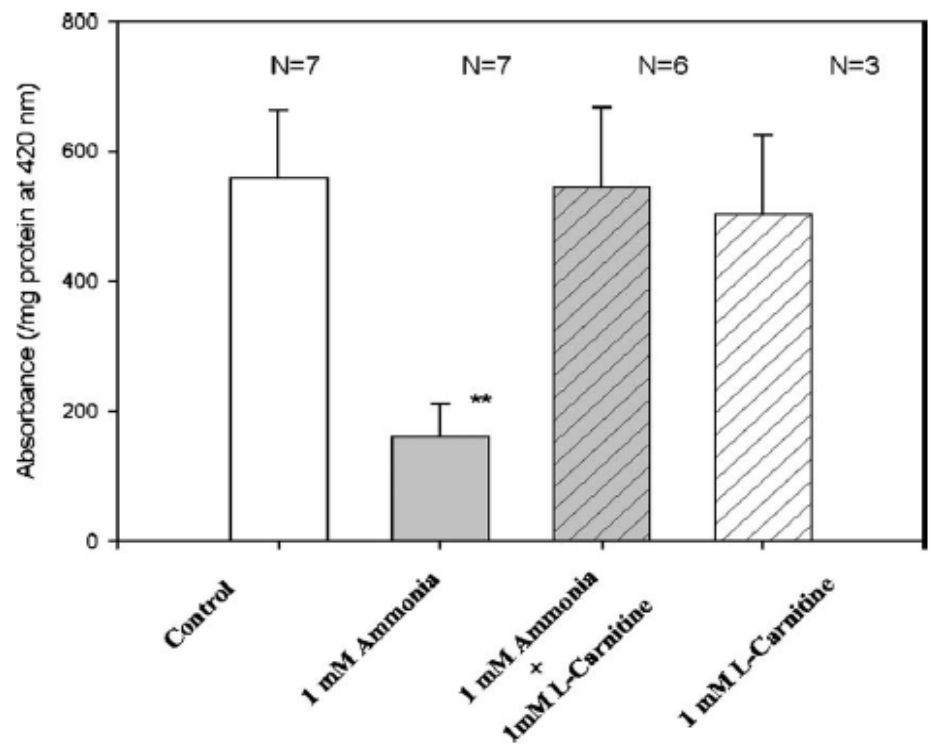

Fig. 4. (from Izumi et al., 2005). Effects of ammonia and L-carnitine on mitochondrial function. The WST-1 mitochondrial dehydrogenase assay (optical density measurements at $420 \mathrm{~nm}$ ) was performed $1 \mathrm{~h}$ after pre-incubation with ammonia in the absence and presence of L-carnitine. $P^{* *}<0.01$ by paired Student's $t$ test.

Similarly, DL-APV, an antagonist of NMDA receptors, diminished the effects of ammonia on reduced ATP levels and inhibition of long-term potentiation. These in vitro data suggest that L-carnitine and NMDA receptor antagonists have the potential to preserve neuronal 
function during HA, confirming results obtained in vivo in hyperammonemic animals (see above). Minana et al. (2002) compared the in vivo and in vitro effects of different trimethylamine-containing compounds on ammonia toxicity in mice and against glutamate and NMDA toxicity in primary cultures of neurons (Tables 1 and 2).

\begin{tabular}{|llll|}
\hline & & \multicolumn{2}{c|}{ Survival } \\
\cline { 3 - 4 } Compound & Dose & Survivors/Injected & \\
& & & \\
& nmol/kg & & \\
None & & $17 / 142$ & 12 \\
L-carnitine & 16 & $24 / 28$ & 86 \\
D-carnitine & 16 & $21 / 31$ & 68 \\
Betaine & 16 & $12 / 20$ & 60 \\
TMAO & 8 & $32 / 50$ & 64 \\
Choline & 1.6 & $43 / 65$ & 57 \\
Acetylcholine & 0.28 & $17 / 30$ & 71 \\
Acetylcholine & 0.55 & $63 / 88$ & 51 \\
Carbachol & 0.0028 & $14 / 30$ & 76 \\
Carbachol & 0.0055 & $23 / 49$ & 80 \\
Acetylcarnitine & 6 & $41 / 54$ & \\
Isovalerylcarnitine & 4 & $17 / 21$ & \\
\end{tabular}

Table 1. (adapted from Minana et al., 2002). Protective effect of different compounds against acute ammonia toxicity. Groups of mice were injected i.p. with the indicated doses of each compound. Fifteen minutes later, the mice were injected i.p. with $14 \mathrm{mmol} / \mathrm{kg}$ of ammonium acetate. All values are statistically different from mice injected only with ammonia.

\subsubsection{L-carnitine in human hepatic encephalopathy}

As mentioned above, experimental HA is not a model of human liver disease and rather serves to investigate the neurotoxicity of acute or chronic ammonia exposure or to study specific aspects of liver failure (Belanger \& Butterworth, 2005). Therefore, very few studies that investigate the effects of L-carnitine in appropriate animal models of HE have been published. Clinical studies in humans with HE have only been performed by a few groups to date. Nevertheless, in initial clinical studies (del Olmo et al., 1990), the effect of L-carnitine on HA in patients with cirrhosis, subjected to a rectal ammonium overload test, was investigated. On comparing 40 cirrhotic patients given L-carnitine with 40 control cirrhotics given a placebo, no significant differences were observed in ammonium levels. However, on studying the patients with the greatest liver involvement, those given L-carnitine showed smaller elevations in ammonia and better responses to psychometric tests than those receiving the placebo. These data provided the first evidence on the effect of L-carnitine on ammonia clearance and pointed to the importance of further investigations. 


\begin{tabular}{|c|c|c|c|c|c|c|}
\hline \multirow{2}{*}{ Compound } & \multirow{2}{*}{ Dose } & Glu & tamate & \multicolumn{3}{|c|}{ NMDA } \\
\hline & & \multicolumn{3}{|c|}{ Surviving neurons } & & \\
\hline None & & 20 & \pm & 28 & \pm & 7 \\
\hline Carnitine & $0.5 \mathrm{mM}$ & 70 & \pm 8 & 47 & \pm & 8 \\
\hline Betaine & $1 \mathrm{mM}$ & 69 & \pm 7 & 46 & \pm & 5 \\
\hline TMAO & $1 \mathrm{mM}$ & 75 & \pm 4 & 64 & \pm & 12 \\
\hline Choline & $1 \mathrm{mM}$ & 65 & \pm 5 & 41 & \pm & 5 \\
\hline Acetylcholine & $1 \mathrm{mM}$ & 68 & \pm 4 & 23 & \pm & $11 \mathrm{NS}$ \\
\hline Carbachol & $1 \mathrm{mM}$ & 73 & \pm 3 & 40 & \pm & 6 \\
\hline Acetylcarnitine & $1 \mu \mathrm{M}$ & 69 & \pm 3 & 48 & \pm & 8 \\
\hline Trans-ACPD & $0.1 \mathrm{mM}$ & 84 & \pm & 65 & \pm & 5 \\
\hline MK-801 & $20 \mathrm{nM}$ & 80 & \pm & 83 & \pm & 6 \\
\hline
\end{tabular}

Table 2. (adapted from Minana et al., 2002). Effects of trimethylamine-containing compounds on neuronal death induced by glutamate or NMDA. Neurons were incubated with these compounds for $15 \mathrm{~min}$ and then $1 \mathrm{mM}$ glutamate or $0.5 \mathrm{mM}$ NMDA was added to the plates. Neuronal survival was determined $4 \mathrm{~h}$ later by staining with fluorescein diacetate and propidium iodide.

Based on previous experiments in animal models, such as the rat model of ammoniaprecipitated encephalopathy (Therrien et al., 1997), in a clinical randomized placebocontrolled study, 120 patients with moderate HE due to cirrhosis were treated for 60 days with L-carnitine (2 g twice a day) (Malaguarnera et al., 2003). The study demonstrated a protective effect of L-carnitine in ammonia-precipitated encephalopathy in these patients after 30 days, which was more pronounced after 60 days of treatment. Concomitantly, a significant therapeutic effect of L-carnitine was observed in a psychometric test. Also, in 50 patients infected with HCV and development of chronic hepatitis, the effect of L-carnitine on interferon (IFN)-alpha-induced fatigue was evaluated (Neri et al., 2003). Fatigue is a common complaint in patients with liver disease, and can be induced also by IFN. Patients treated with IFN and L-carnitine show a marked and early significant reduction of fatigue levels compared to untreated patients. It has been suggested from these data, taking into account the severity of this symptom in this study, that L-carnitine could be used as an energetic substrate in IFN-treated patients, leading to a better response to this side effect. However, the mechanisms by which L-carnitine might exert a protective effect based on energy metabolism still remain to be investigated.

In 2005, Malaguarnera et al. continued to work with these data and evaluated the influence of L-carnitine on mental conditions and ammonia effects on patients with minimal or moderate HE due to different liver diseases, in a randomized, placebo-controlled study. The patients were randomized into an L-carnitine receiving group ( $2 \mathrm{~g}$ twice daily for 90 days) and a placebo-receiving group in a double-blind test. The results showed a protective effect of L-carnitine against ammonia-precipitated encephalopathy in cirrhotic patients, together with a significant decrease in ammonia fasting serum levels. After 30 days of treatment, 
ammonia serum levels were significantly decreased, with an ongoing trend after 60 and 90 days. Psychometric tests also clarified a significant therapeutic effect.

Based on data suggesting a protective effect of L-carnitine on HA-induced neuronal dysfunction, eighteen cirrhotic patients with $\mathrm{HE}$ and HA received a single dose of $0.5 \mathrm{~g}$ acetyl-L-carnitine to investigate its effects on neuronal function (Siciliano et al., 2006). The effects of acute acetyl-L-carnitine administration were studied by pattern-reversal visualevoked potentials (VEP) to evaluate neuronal function. The results showed a rapid effect of a single dose of acetyl-L-carnitine. It was suggested that it transiently improves neuronal function in cirrhotic patients with persistent HE and HA. However, there was no change in plasma ammonia levels. In contrast to most animal studies, these results suggest a direct effect of acetyl-L-carnitine on the CNS with as yet unknown mechanisms.

In another evaluation, Malaguarnera et al. (2006) investigated the efficacy of acetyl-Lcarnitine in the treatment of hepatic coma in a randomized placebo-controlled study. The patients received either acetyl-L-carnitine or a placebo ( $4 \mathrm{~g}$ intravenously over 3 hours, once a day for 3 days). A significant improvement in neurological symptoms and decrease in EEG grade, together with a reduction of ammonia plasma levels, were obvious at 1 to 4 hours after treatment and remained until 24 hours after. An extended study by Malaguarnera et al. (2008) evaluated the cognitive function of 125 cirrhotic patients with minimal HE after treatment with acetyl-L-carnitine ( $2 \mathrm{~g}$ twice a day for 90 days). These results showed a considerable improvement in neuropsychological functions and a significant reduction in serum ammonium levels, further confirming neuronal improvements after L-carnitine treatment.

\subsubsection{Preliminary results on metabolic alterations using multinuclear NMR spectroscopy}

High-resolution Nuclear Magnetic Resonance (NMR) approaches using stable isotopes are now yielding large amounts of detailed information on cerebral metabolic compartmentalization and neuronal-glia interactions (Zwingmann \& Leibfritz, 2003). In order to investigate the effect of L-carnitine on energy metabolism, ${ }^{1} \mathrm{H}$ - and ${ }^{13} \mathrm{C}-\mathrm{NMR}$ spectroscopy was used to measure metabolic pathways in brain and muscle following administration of [U-13C]glucose $(500 \mathrm{mg} / \mathrm{kg}$; i.p.) to rats with mild $\mathrm{HE}$ and in rats with ammonia-precipitated encephalopathy. As a model of mild $\mathrm{HE}$, we investigated rats four weeks after an end-to-side portacaval anastomosis (PCA). During the last 7 days, rats with PCA and controls were administered daily either L-Carnitine $(0.8 \mathrm{mmol} / \mathrm{kg}$; i.p. $)$ or saline. After administration of [U-13C]glucose for 15 to 60 minutes, the rats were sacrificed. The frozen tissue samples of brain and muscle were powdered over liquid nitrogen and homogenized in perchloric acid (PCA) at $0^{\circ} \mathrm{C}$. Homogenates were centrifuged, the supernatants neutralized, precipitated $\mathrm{KClO}_{4}$ sedimented, and the supernatants lyophilized. The lyophilized samples were dissolved in $600 \mu \mathrm{D} 2 \mathrm{O}$, centrifuged and neutralized $(\mathrm{pH}=$ 6.8). The pellet after the first centrifugation step was homogenized in water and lyophilized. The lyophilized samples were dissolved in $800 \mu \mathrm{lCDCl} / \mathrm{CD} 3 \mathrm{OD}$ to obtain the fatty acid components. All animals received humane care according to the criteria outlined in the "Guide for the Care and Use of Laboratory Animals" prepared by the National Academy of Sciences and published by the National Institutes of Health (NIH publication 6-23 (revised), 1985). 
As a neurobehavioral measure, locomotor activities were measured using a computerized Auto-Track system (Columbus Instruments, OH), consisting of a 15-by-15 infrared beam array with an interbeam distance of $2.4 \mathrm{~cm}$ along the $X$ and $Y$ axis. Data were collected every $0.1 \mathrm{~s}$ and the activity was categorized as ambulatory, stereotypic, or resting. The animal activity meter was installed in a quiet isolated room with $12 \mathrm{~h}$ light/12 h dark cycles. One hour after HAL, the animals were placed individually in the auto-track system and data acquisition was started for a period of $24 \mathrm{hr}$. PCA in the rat resulted in a broad spectrum of neurobehavioral changes, such as an $80 \%$ impaired locomotor activity, which was largely prevented by L-carnitine (Fig. 5).

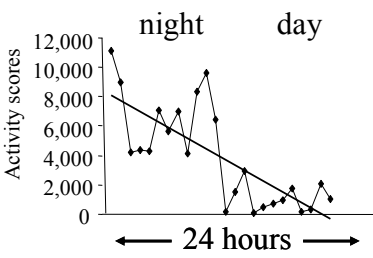

Sham
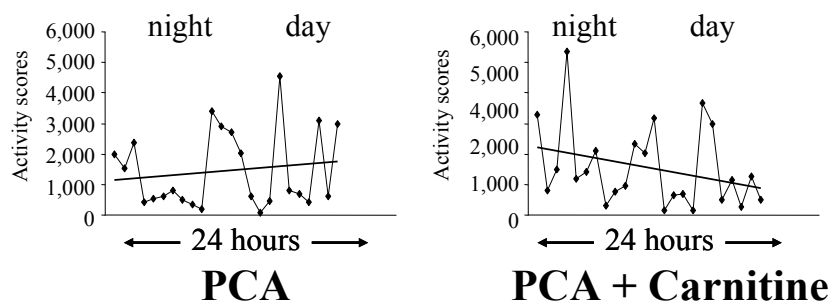

Fig. 5. Night and day locomotor activity in rats with PCA with or without treatment with Lcarnitine.

Stable isotope spectroscopic methods make it possible to measure the output of interrelated pathways concurrently and determine several atoms (e.g. ${ }^{1} \mathrm{H}$ and ${ }^{13} \mathrm{C}$ ) without transformation or isolation processes (Zwingmann \& Leibfritz, 2003). The metabolic pathways by which the ${ }^{13} \mathrm{C}$-label from $\left[1-{ }^{13} \mathrm{C}\right]$ glucose is transformed into various metabolites are presented in simplified form in Fig. 6. For a more detailed description of the metabolic pathways from ${ }^{13}$ C-labelled glucose isotopomers, see Zwingmann \& Leibfritz (2003). Briefly, via the glycolytic pathway, [1-13C]glucose is transformed into [3-13 C]pyruvate, $\left[3-{ }^{13} \mathrm{C}\right]$ alanine and $\left[3-{ }^{13} \mathrm{C}\right]$ lactate. $\left[3-{ }^{13} \mathrm{C}\right]$ pyruvate may enter the TCA cycle via the anaplerotic pathway (pyruvate carboxylase, PC (or malic enzyme (ME)) or the oxidative pathway (pyruvate dehydrogenase, PDH). Via PC, glutamate and glutamine are labelled at C-2. In the oxidative pathway, pyruvate enters the cycle as $\left[2-{ }^{13} \mathrm{C}\right]$ acetyl-CoA, and glutamate and glutamine are mono-labelled at C-4.

The data show that PCA in rats resulted in a decreased flux through PDH, a key enzyme for mitochondrial metabolism, which is primarily present in the neurons. Concomitant treatment with L-carnitine eliminated this effect over the levels of sham-operated controls (Fig. 7).

Another group of rats received ammonium acetate $(3.8 \mathrm{mmol} / \mathrm{kg}$; i.p.) four weeks after PCA to precipitate encephalopathy. L-carnitine was concomitantly administered in a single dose $(1.6 \mathrm{mmol} / \mathrm{kg}$; i.p.). In rats with ammonia-precipitated encephalopathy, treatment with Lcarnitine delayed the time to the onset of coma (Fig. 8). Animals in which both righting ability and corneal reflex were affected were considered to be in coma. Rats with ammoniaprecipitated encephalopathy and rats treated with L-carnitine were sacrificed at the same time points. 


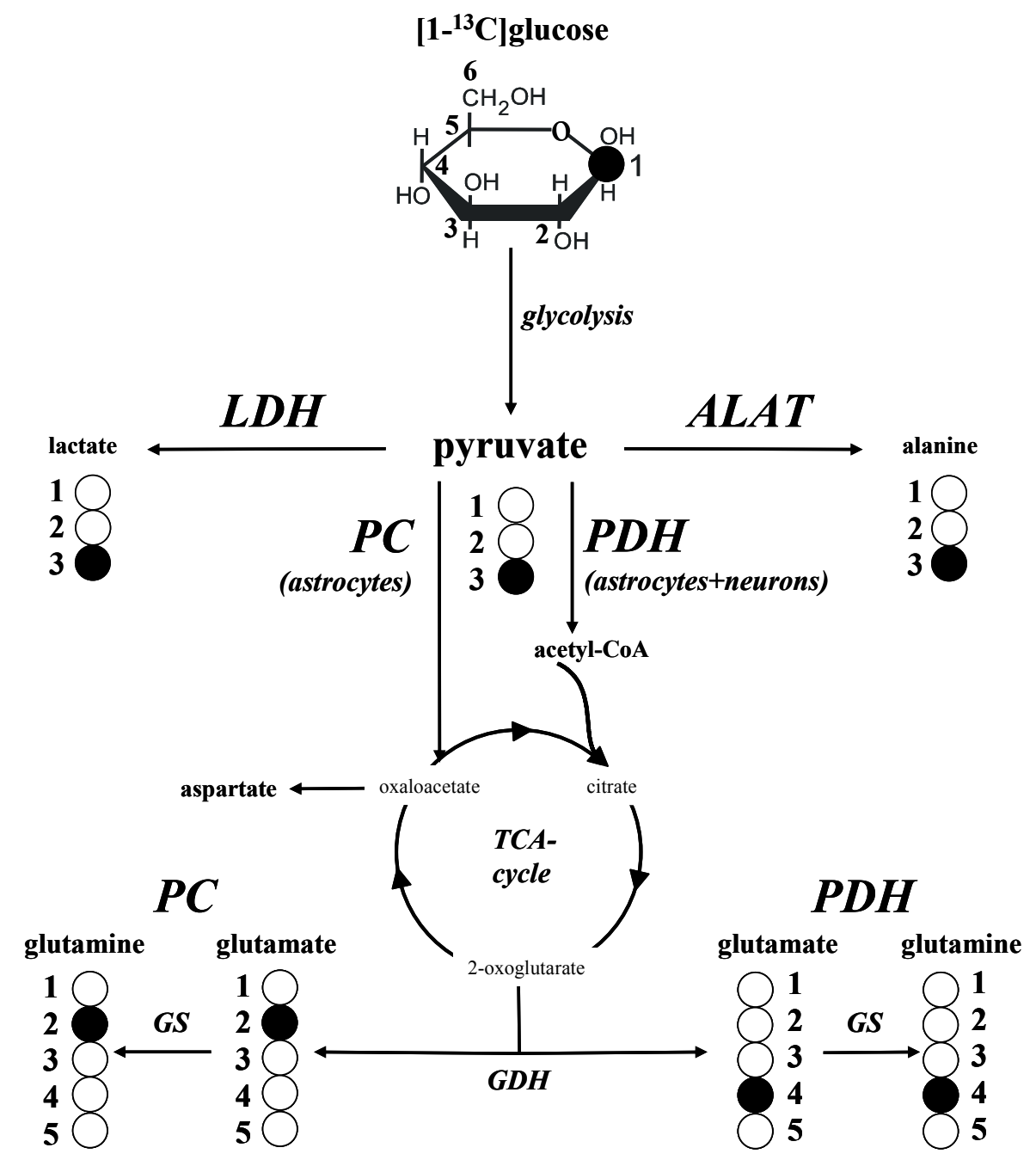

Fig. 6. Labelling of metabolites from $\left[1-{ }^{13} \mathrm{C}\right]$ glucose. Label distribution in glycolytic and TCA cycle intermediates during metabolism of [1-13C]glucose. A single turn of the TCA cycle from pyruvate via PC (pyruvate carboxylase) or PDH (pyruvate dehydrogenase) to 2oxoglutarate and subsequently glutamate and glutamine is considered. A description of the pathways leading to the different isotopomers is provided in the text. $\mathrm{LDH}$ : lactate dehydrogenase; ALAT: alanine aminotransferase; GDH: glutamate dehydrogenase; GS: glutamine synthetase. 


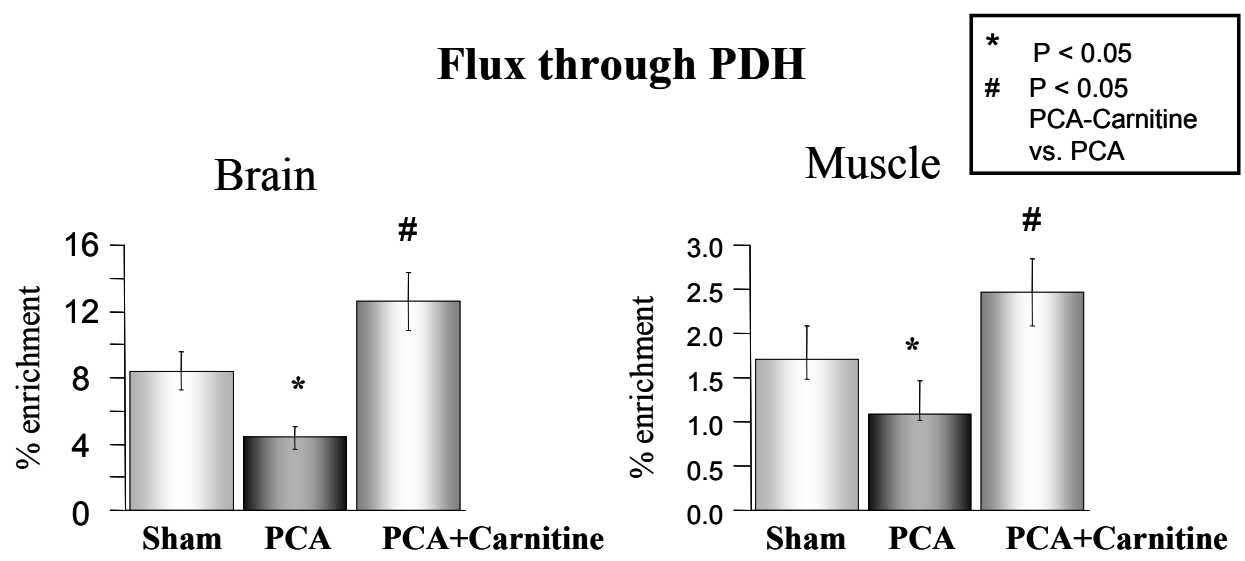

Fig. 7. Effect of L-carnitine on mitochondrial metabolism in rats with mild HE. [U-13C]glucose flux through the Krebs cycle was measured by the de novo synthesis of glutamate through PDH 12 hours after the last administration of L-carnitine or saline.

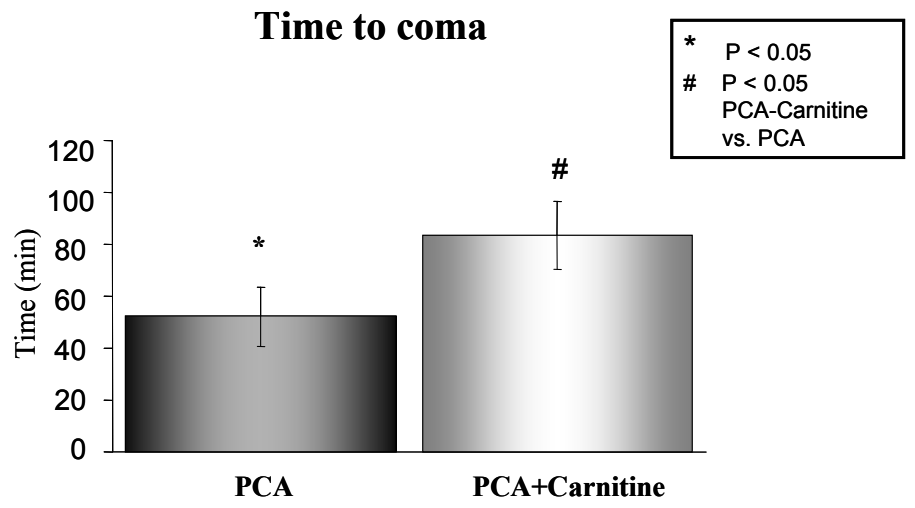

Fig. 8. Time to the onset of coma in rats with ammonia-precipitated encephalopathy.

Elevated brain lactate is a phenomenon which is characteristic of both human and experimental HE. As an indirect measurement of mitochondrial Krebs cycle metabolism, we measured the de novo synthesis of lactate from ${ }^{13} \mathrm{C}$-labelled glucose in rats with ammoniaprecipitated encephalopathy without and with treatment with L-carnitine (Fig. 9). The data showed that treatment with L-carnitine significantly eliminated the rise in brain lactate in these animals.

These preliminary data demonstrate that in chronic HE, L-carnitine acts on both brain and muscle by improving mitochondrial metabolism. These data further demonstrate that Lcarnitine prevents increased lactate synthesis in ammonia-precipitated encephalopathy, which parallels a significant increase in the time to coma. 


\section{Lactate synthesis}

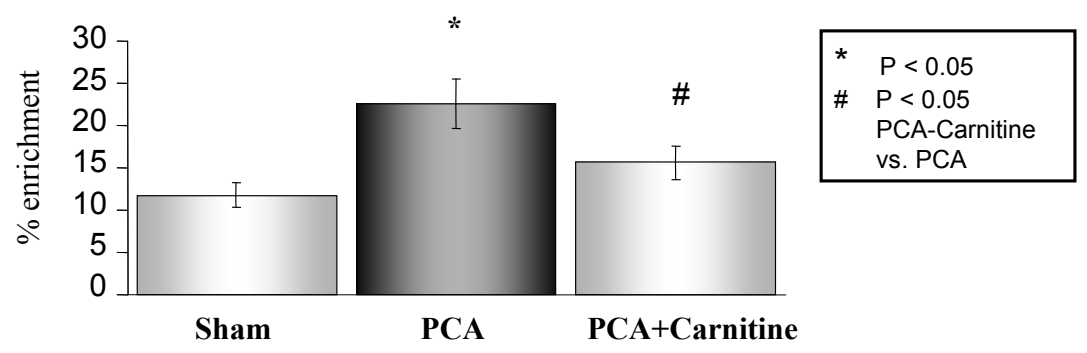

Fig. 9. Effect of L-carnitine on glycolytic lactate synthesis in rats with ammonia-precipitated encephalopathy. [U-13C]glucose flux through glycolysis was measured by the de novo synthesis of lactate.

\section{Concluding remarks}

To date, few studies have investigated the effect of L-carnitine and its derivates in human hyperammonemic syndromes and HE. However, in hyperammonemic animal models and ammonia-exposed cultured neurons L-carnitine has been shown to counteract some of the neurotoxic effects of ammonia. These data clearly show that L-carnitine is able to reduce ammonia levels, increase energy metabolism and decrease mortality. These studies further prove that HA is a key factor in HE. A protective effect of L-carnitine against disordered mental function and ammonia-precipitated encephalopathy was also observed in cirrhotic patients with HE, together with lowered circulating ammonia levels. These clinical trials are promising as they clarify that L-carnitine can reduce ammonia levels and improve patient performance in HE. The molecular mechanisms of the action of L-carnitine have not yet been fully elucidated, although the results suggest an effect on neuronal function in HE.

$\mathrm{HE}$ is a disorder that morphologically primarily affects the astrocytes (Norenberg, 1998). The dysfunction of astrocytes includes deficits in their ability to take up glutamate from the extracellular space, which may lead to abnormal glutamatergic neurotransmission. However, a series of studies has also demonstrated that ammonia directly causes disorders in neuronal function and neurotransmitter homeostasis by acting on glutamatergic receptors and by synthesis of neurotransmitters, i.e. glutamate and GABA. Furthermore, in recent studies an inhibition of neuronal energy metabolism in the TCA cycle has been proposed. Animal and cell culture studies have indicated that ammonia impairs neuronal function via altered metabolism and ultimately NMDA receptor activation, and that L-carnitine and NMDA receptor antagonists have the potential to preserve neuronal function during HA. Lcarnitine and its derivates increase energy metabolism via the TCA cycle by activation of fatty acid oxidation. They are able to change the activities of several enzymes involved in fatty acid metabolism, increase the synthesis of phospholipids and provide acetyl groups for the synthesis of acetylcholine. Furthermore, they can modify membrane fluidity and surface charge, which lead to altered activity of membrane transporter and enzymes. Since the brain can sustain part of its energy metabolism by fatty acid catabolism, the role of astrocytes and their energy metabolism in L-carnitine therapy needs further experimental clarification. 
The treatment of HA is uncertain and mostly directed to reducing the level of circulating ammonia. There is currently no therapy designed to counteract the molecular effects of ammonia. A further question remains as to whether the protective effects of L-carnitine against the toxicity of ammonia are systemic. In most studies, L-carnitine reduces circulating ammonia levels, suggesting a systemic effect of L-carnitine. For example, L-carnitine has been shown to have direct effects on the liver in patients with steatosis (Romano et al., 2008), and Benzerrouk and Qureshi (2001) demonstrated that acetyl-L-carnitine has a modulating effect on several hepatic mitochondrial matrix and inner membrane proteins that are modified by HA in the spf mutant mouse. On the other hand, L-carnitine seems to have direct effects on cerebral metabolism in valproic acid toxicity in the absence of hepatocellular dysfunction (Sztajnkrycer, 2002).

Another question to be clarified is why the effects of L-carnitine differ from its derivative acetyl-L-carnitine. When compared with L-carnitine, for example, acetyl-L-carnitine better preserved ATP in the brain of hyperammonemic mice, while it lowered ammonia in the blood and brain less markedly. One reason for this apparent discrepancy may lie in the use of the acetyl residue by the brain. This, on the other hand, points to an additional effect of this L-carnitine derivative on astrocytic energy metabolism, since acetate is taken up selectively by astrocytes while neurons do not use acetate (Waniewski and Martin, 1998; Zwingmann \& Leibfritz, 2003). On the other hand, there could be a close correlation between changes in astrocytic energy metabolism and neuronal (dys)function. In particular, L-carnitine exerts its effects in part by changes in NMDA receptor activation. Ammonia and extracellular glutamate cause an overactivation of this receptor, which in turn produces NO resulting in nitration-mediated inhibition of proteins such as the ammonia-detoxifying glutamine synthetase in the astrocytes. Improved energy metabolism in the astrocytes might counteract this deficit as well as a possible effect of ammonia on the astrocytic TCA cycle (Chatauret et al., 2003). The molecular and cell-specific energetic effects of L-carnitine and acetyl-L-carnitine therefore require further clarification.

Taken together, these results show that L-carnitine and its analogues do have the potential to suppress the neurotoxicity of ammonia. The fact that the action of acetyl-L-carnitine may differ from that of L-carnitine suggests that the classical function of L-carnitine is not the sole mechanism underlying the suppression of the neurotoxicity of ammonia (Matsuoka \& Igisu, 1993). However, further investigations are required to clarify the molecular mechanisms that lead to the protective effects of L-carnitine and its derivates in both experimental HA and human HE. Other studies may also optimize the dosage and time of administration of L-carnitine. Analysis of selected L-carnitine trials compared to currently accepted therapies suggests that L-acyl-carnitine is promising as a safe and effective treatment for HE, and further trials of this drug are warranted (Shores \& Keeffe, 2008). Since it is a low-cost agent with few side effects, further clinical trials could prove to be promising in evaluating the broader use of L-carnitine and derivatives in patients with minimal or ammonia-precipitated HE.

\section{Acknowledgements}

This work was funded by the Canadian Instituts for Health Research (CIHR). Dr. Zwingmann is a recipient of supporting awards from the Quebec Ministry of Education, the Programme québécois de bourses d'excellence, the Deutsche Forschungsgemeinschaft 
(German Research Foundation, DFG) and the Fonds de Recherche en santé du Quebec (FRSQ).

\section{References}

Bachmann, C. (2002). Mechanisms of hyperammonemia. Clin Chem Lab Med, Vol. 40, pp. 653662

Bass, N. M. (2007), Review article: the current pharmacological therapies for hepatic encephalopathy. Aliment Pharmacol Ther, Vol. 25, Suppl.1, pp. 23-31

Bates, T.E., Williams, S.R. Kauppinen, R.A., \& Gadian, D.G. (1989). Observation of cerebral metabolites in an animal model of acute liver failure in vivo: a ${ }^{1} \mathrm{H}$ and ${ }^{31} \mathrm{P}$ nuclear magnetic resonance study. J Neurochem, Vol. 53, pp. 102-110

Beal, M. F. (2003), Bioenergetic approaches for neuroprotection in Parkinson's disease. Ann Neuro., Vol. 53, Suppl 3, pp. S39-S47

Belanger, M., \& Butterworth, R.F. (2005). Acute liver failure: a critical appraisal of available animal models. Metab. Brain Dis, Vol 20, pp. 409-423

Benzerrouk R., \& Qureshi I. A. (2001). Hepatic mitochondrial proteins in congenitally hyperammonemic spf mice: effect of acetyl-L-carnitine. Biosci Biotechno. Biochem, Vol. 65, pp. 495-500

Blei, A.T. (2001), Pathophysiology of brain edema in fulminant hepatic failure, revisited. Metab Brain Dis, Vol. 16, pp. 85-94

Bremer, J. (1983), Carnitine - metabolism and functions. Physiol Rev, Vol 63, pp. 1420-1480

Butterworth, R.F., Giguere, J.F., Michaud, J., Lavoie, J., \& Layrargues, G.P. (1987). Ammonia: key factor in the pathogenesis of hepatic encephalopathy. Neurochem Pathol, Vol 6, pp. 1-12

Butterworth, R.F. (1998). Effects of hyperammonaemia on brain function. J Inherit Metab Dis, Vol. 21 Suppl 1, pp. 6-20

Butterworth, R. F. (2002). Glutamate transporters in hyperammonemia. Neurochem Int Vol. 41, pp. 81-85

Cammà, C., Fiorello, F., Tinè, F., Marchesini, G., Fabbri, A., \& Pagliaro, L. (1993). Lactitol in treatment of chronic hepatic encephalopathy. Dig Dis Sci, Vol. 38, pp. 916-922

Cauli, O., Rodrigo, R., Boix, J., Piedrafita, B., Agusti, A., \& Felipo, V. (2008). Acute liver failure-induced death of rats is delayed or prevented by blocking NMDA receptors in brain. Am J Physiol Gastrointest Liver Physio., Vol. 295, pp. G503-511

Chan, Y. C., Tse, M. L., \& Lau, F. L. (2007). Two cases of valproic acid poisoning treated with L-carnitine. Hum Exp Toxicol, Vol. 26, pp. 967-969

Chatauret, N., Zwingmann, C., Rose, C., Leibfritz, D., \& Butterworth, R.-F. (2003). Effects of hypothermia on brain glucose metabolism in acute liver failure: a H/C-nuclear magnetic resonance study. Gastroenterology, Vol. 125, pp. 815-824

Chiechio, S., Copani, A., Gereau, R. W. 4th, \& Nicoletti, F. (2007). Acetyl-L-carnitine in neuropathic pain: experimental data. CNS Drugs, Vol. 21 Suppl 1, pp. 31-38.

Chung, C., Gottstein, J., \& Blei, A.T. (2001), Indomethacin prevents the development of experimental ammonia-induced brain edema in rats after portacaval anastomosis. Hepatology, Vol. 34, pp. 249-254

Cordoba, J., \& Blei, A.T. (1995). Cerebral edema and intracranial pressure monitoring. Liver Transpl Surg, Vol. 1, pp. 187-194 
Cordoba, M. D., \& Minguez, M. D. (2008). Hepatic encephalopathy. Semin Liver Dis, Vol. 28, pp. $70-80$

Del Olmo, J.A., Castillo, M., Rodrigo, J.M., Aparisi, L., Serra, M.A., Wassel, A., \& Bixquert, M. (1990). Effect of L-carnitine upon ammonia tolerance test in cirrhotic patients. Adv Exp Med Biol, Vol. 272, pp. 197-208

Deutz, N.E.P., De Graaf, A.A., De Haan, J.G., Bovée, W.M.M.J., \& Chamuleau, R.A.F.M., (1988). In vivo brain ${ }^{1} \mathrm{H}-\mathrm{NMR}$ spectroscopy (1H-NMRS) during acute hepatic encephalopathy (HE). In: Soeters PB, Wilson JHP, Meijer AJ and Holm E, eds. Advances in Ammonia Metabolism and Hepatic Encephalopathy. Chap. 57. Amsterdam: Excerpta Media, 1988; pp. 439-446

Ebert, D., Haller, R. G., \& Walton, M. E. (2003). Energy contribution of octanoate to intact brain metabolism measured by ${ }^{13} \mathrm{C}$ nuclear magnetic resonance. J Neurosci, Vol. 23, pp. 5928-5935

Felipo, V., Minana, M.D., Cabedo, H., \& Grisolia, S. (1994). L-carnitine increases the affinity of glutamate for quisqualate receptors and prevents glutamate neurotoxicity. Neurochem Res, Vol. 19, pp. 373-377

Ferenci, P., Lockwood, A., Mullen, K., Tarter, R., Weissenborn, K., \& Blei, A. T. (2002). Hepatic encephalopathy - definition, nomenclature, diagnosis, and quantification: final report of the working party at the 11th World Congresses of Gastroenterology, Vienna, 1998. Hepatology, Vol. 35, pp. 716-721

Fornasini, G., Upton, R. N., \& Evans, A. M. (2007). A pharmacokinetic model for L-carnitine in patients receiving haemodialysis. Br J Clin Pharmacol, Vol. 64, pp. 335-345

Häussinger, D., \& Schliess, F. (2008). Pathogenic mechanisms of hepatic encephalopathy. Gut, Vol. 57, pp. 1156-1165

Holmin, T., Agardh, C.-D. Alinder, G., Herlin, P., \& Hultberg B. (1983). The influence of total hepatectomy on cerebral energy state, ammonia-related amino acids of the brain and plasma amino acids in the rat. Eur J Clin Invest, Vol. 13, pp. 215-220

Hoyumpa, A.M. Jr., Desmond, P.V., Avant, G.R., \& Roberts, R.K. (1979). Hepatic encephalopathy. Gastroenterology, Vol. 76, pp. 184-195

Inazu, M., Matsumiya, T. (2008). [Physiological functions of carnitine and carnitine transporters in the central nervous system]. Nihon Shinkei Seishin Yakurigaku Yasshi, Vol. 28, pp. 113-120

Izumi, Y., Izumi, M., Matsukawa, M., Funatsu, M., \& Zorumski, C.F. Ammonia-mediated LTP inhibition: effects of NMDA receptor antagonists and L-carnitine. Neurobiol Dis, Vol. 20, pp. 615-624

Jayakumar, A.R., Panickar, K.S., Murthy, Ch.R., \& Norenberg, M.D. (2006). Oxidative stress and mitogen-activated protein kinase phosphorylation mediate ammonia-induced cell swelling and glutamate uptake inhibition in cultured astrocytes. J Neurosci, Vol. 26, pp. 4774-4784

Kala, G., \& Hertz, L. (2005). Ammonia effects on pyruvate/lactate production in astrocytes - interaction with glutamate. Neurochem Int, Vol. 47, pp. 4-12

Kircheis, G., Wettstein, M., Timmermann, L., Schnitzler, A., \& Häussinger, D. (2002a). Critical flicker frequency for quantification of low-grade hepatic encephalopathy. Hepatology, Vol. 35, pp. 357-366 
Kircheis, G., Wettstein, M., Dahl, S., \& Häussinger, D. (2002b). Clinical efficacy of Lornithine-L-aspartate in the management of hepatic encephalopathy. Metab Brain Dis, Vol. 17, pp. 453-462

Kosenko, E., Kaminsky, Y., Lopata, O., Muravyov, N., Kaminsky, A., Hermenegildo, C., \& Felipo V. (1998). Nitroarginine, an inhibitor of nitric oxide synthase, prevents changes in superoxide radical and antioxidant enzymes. Metab Brain Dis, Vol. 13, pp. 29-41

Kosenko, E., Kaminski, Y, Lopata, O., Muravyov, N., \& Felipo V. (1999). Blocking NMDA receptors prevents the oxidative stress induced by acute ammonia intoxication. Free Radic Bio. Med, Vol. 26, pp. 1369-374.

Kuratsune, H., Yamaguti, K., Lindh, G., Evengard, B., Hagberg, G., Matsumura, K., Iwase, M., Onoe, H., Takahashi, M., Machii, T., Kanakura, Y., Kitani, T., Langstrom, B., \& Watanabe, Y. (2002). Brain regions involved in fatigue sensation: reduced acetylcarnitine uptake into the brain. Neuroimage, Vol. 17, pp. 1256-1265

Lai, J. C., \& Cooper, A. J. (1986). Brain alpha-ketoglutarate dehydrogenase complex: kinetic properties, regional distribution, and effects of inhibitors. J Neurochem, Vol. 47, pp. 1376-1386

Larsen, F.S., Gottstein, J., \& Blei A.T. (2001). Cerebral hyperemia and nitric oxide synthase in rats with ammonia-induced brain edema. J Hepatol, Vol. 34, pp. 548-554

Leevy, C. B., \& Phillips J. A. (2007). Hospitalizations during the use of rixafimin versus lactulose for the treatment of hepatic encephalopathy. Dig Dis Sci, Vol. 52, pp. 737741

Lheureux, P. E., Penaloza, A., Zahir, S., \& Gris, M. (2005). Science review: carnitine in the treatment of valproic acid-induced toxicity - what ist he evidence? Crit Care, Vol. 9, ppp. 431-440

Llansola, M., Erceg, S., Hernandez-Viadel, M., \& Felipo, V. (2002). Prevention of ammonia and glutamate neurotoxicity by carnitine: molecular mechanisms. Metab Brain Dis, Vol. 17, pp. 389-397

Llansola, M., \& Felipo V. (2002). Carnitine prevents NMDA receptor-mediated activation of MAP-kinase and phosphorylation of microtubule-associated protein 2 in cerebellar neurons in culture. Brain Res, Vol. 947, pp. 50-56.

Lockwood, A.H., McDonald, J.M., Reiman, R.E., Gelbard, A.S., Laughlin, J.S., Duffy, T.E., \& Plum, F. (1979). The dynamics of ammonia metabolism in man. Effects of liver disease and hyperammonemia. J Clin Invest, Vol. 63, pp. 449-460

Longo, N., Amat di San Filippo, C., \& Pasquali, M. (2006). Disorders of carnitine transport and the carnitine cycle. Am J Med Genet C Semin Med Genet, Vol. 142C, pp. 77-85

Luppa, D. (2004). Beteiligung von L-Carnitin an der Regulation des Fett- und Kohlenhydratstoffwechsels. Klinische Sportmedizin, Vol. 5, pp. 25-34.

Malaguarnera, M., Pistone, G., Astuto, M., Dell'Arte, S., Finocchiaro, G., Lo Giudice, E., \& Pennisi, G. (2003). L-Carnitine in the treatment of mild or moderate hepatic encephalopathy. Dig Dis Sci, Vol. 21, pp. 271-275

Malaguarnera, M., Pistone, G., Elvira, R., Leotta, C., Scarpello, L., \& Liborio, R. (2005). Effects of L-carnitine in patients with hepatic encephalopathy. World J Gastroentero., Vol. 11, pp. 7197-7207 
Malaguarnera, M., Pistone, G., Astuto, M., Vecchio, I., Raffaele, R., Lo Giudice, E., \& Rampello, L. (2006). Effects of L-acetylcarnitine an cirrhotic patients with hepatic coma: randomized double-blind, placebo-controlled trial. Dig Dis Sci, Vol. 51, pp. 2242-2247

Malaguarnera, M., Cammalleri, L., Gargante, M. P., Vacante, M., Colonna, V., \& Motta, M. (2007). L-carnitine treatment reduces severity of physical and mental fatigue and increases cognitive functions in centenarians: a randomized and controlled clinical trial. Am J Clin Nutr, Vol. 86, pp. 1738-1744

Malaguarnera, M., Gargante, M. P., Cristaldi, E., Vacante, M., Risino, C., Cammalleri, L., Pennisi, G., \& Rampello, L. (2008). Acetyl-L-carnitine treatment in minimal hepatic encephalopathy Dig Dis Sci, Vol. 53, pp. 3018-25

Malaguarnera, M., Gargante, M. P., Cristaldi, E., Colonna, V., Messano, M., Koverech, A., Neri, S., Vacante, M., Cammalleri, L., \& Motta M. (2008). Acetyl L-carnitine (ALC) treatment in elderly patients with fatigue. Arch Gerontol Geriatr, Vol. 46, pp. 181-190

Matsuoka, M., \& Igisu, H. (1993a). Comparison of the effects of L-carnitine, D-carnitine and acetyl-L-carnitine on the neurotoxicity of ammonia. Biochem Pharmacol, Vol. 46, pp. 159-164

Matsuoka, M., \& Igisu, H. (1993b). Effects of L and D-carnitine on brain energy metabolites in mice given sublethal doses of ammonium acetate. Pharmacol Toxicol, Vol. 72, pp. 145-147

McDermott, W.V. Jr. (1957). Metabolism and toxicity of ammonia. N Engl J Med, Vol. 257, pp. 1076-1081

Michalak, A., Rose, C., Butterworth, J., \& Butterworth, R. F. (1996). Neuroactive amino acids and glutamate (NMDA) receptors in frontal cortex of rats with experimental acute liver failure. Hepatology., Vol. 24, pp. 908-913.

Minana, M.D., Hermenegildo, C., Llansola, M., Montoliu, C., Grisolia, S., \& Felipo, V. (1998). Carnitine and choline derivatives containing a trimethylamine group prevent ammonia toxicity in mice and glutamate toxicity in primary cultures of neurons. J Pharm Exp Ther, Vol. 279, pp. 194-199.

Monfort, P., Kosenko, E., Erceg, S., Canales, J.J., \& Felipo, V. (2002). Molecular mechanism of acute ammonia toxicity: role of NMDA receptors. Neurochem Int, Vol. 41, pp. 95-102

Montgomery, S. A., Thal, L. J., \& Amrein, R. (2003). Meta-analysis of double blind randomized controlled clinical trials of acetyl-L-carnitine versus placebo in the treatment of mild codnitive impairment and mild Alzheimer's disease. Int Clin Psychopharmacol, Vol. 18, pp. 61-71

Morgan, M. Y., Blei, A., Grüngreiff, K., Jalan, R., Kircheis, G., Marchesini, G., Riggio, O., \& Weissenborn K. (2007). The treatment of hepatic encephalopathy. Metab Brain Res, Vol. 22, pp. 389-405

Mutomba, M. C., Yuan, H., Konyavko, M., Adachi, S., Yokoyama, C. B., Esser, V., McGarry, J. D., Babior, B. M., \& Gottlieb, R. A. (2000). Regulation of the activity of caspases by L-Carnitine and palmitoylcarnitine. FEBS Lett, Vol. 478, pp. 19-25

Nałecz, K. A., Miecz, D., Berezowski, V., \& Cecchelli, R. (2004). Carnitine: transport and physiological funcions in the brain. Mol Aspects Med, Vol. 25, pp. 551-567

Neri, S., Pistone, G., Saraceno, B., Pennisi, G., Luca, S., \& Malaguarnera, M. (2003). Lcarnitine decreases severity and type of fatigue induced by interferon-alpha in the treatment of patients with hepatitis C. Neuropsychobiology, Vol. 47, pp. 94-97 
Norenberg, M.D. (1977). A light and electron microscopic study of experimental portalsystemic (ammonia) encephalopathy. Progression and reversal of the disorder. Lab Invest, Vol. 36, pp. 618-627

Norenberg, M.D, \& Martinez-Hernandez, A. (1979). Fine structural localization of glutamine synthetase in astrocytes of rat brain. Brain Res, Vol. 161, pp. 303-310

Norenberg, M.D. (1987). The role of astrocytes in hepatic encephalopathy. Neurochem Pathol, Vol. 6, pp. 13-33

Norenberg, M. D. (1998). Astroglial dysfunction in hepatic encephalopathy. Metab Brain Dis, Vol. 13, pp. 319-335

Norenberg, M.D., Jayakumar, A.R., Rama Rao, K.V., \& Panickar, K.S. (2007). New concepts in the mechanism of ammonia-induced astrocyte swelling. Metab Brain Dis, Vol. 22, pp. 219-234

O'Connor, J. E., Costell, M., \& Grisola, S. (1984). Protective effect of L-carnitine on hyperammonemia. FEBS Lett, Vol. 166, pp. 331-334

O'Connor, J. E., Costell, M., \& Grisola, S. (1984a). Prevention of ammonia toxicity by Lcarnitine: metabolic changes in brain. Neurochem Res, Vol. 9, pp. 563-570

Peeling, J., Shoemaker, L., Gauthier, T., Benarroch, A., Sutherland, G.-R., \& Minuk, G.-Y. (1993). Cerebral metabolic and histological effects of thioacetamide-induced liver failure. Am J Physiol, Vol. 265, pp. G572-G578

Pettegrew, J. W., Levine, J., \& McClure, R. J. (2000). Acetyl-L-carnitine physical-chemical, metabolic, and therapeutic properties relevance for its mode of action in Alzheimer's disease and geriatric depression. Mol Psychiatry, Vol. 5, pp. 616-632

Pittler, M.H., \& Ernst E. (2008). Complementary therapies for neuropathic and neuralgic pain: systematic review. Clin J Pain, Vol. 24, pp. 731-733

Rama Rao, K.V., Jayakumar, A.R., \& Norenberg, M.D. (2003). Ammonia neurotoxicity: role of the mitochondrial permeability transition. Metab Brain Dis, Vol. 18, pp. 113-127

Rao K. V., \& Qureshi, I. A. (1999). Reduction in the MK-801 binding sites of the NMDA subtype of glutamate receptor in a mouse model of congenital hyperammonemia: prevention by L-carnitine. Neuropharmacology, Vol. 38, pp. 383-394

Ratnakumari, L., \& Murthy, Ch.R.K. (1993a). Response of rat cerebral glycolytic enzymes to hyperammoniemic states. Neurosci Lett, Vol. 161, pp. 37-40

Ratnakumari, L., Qureshi, I. A., \& Butterworth, R. F. (1993b). Effect of L-carnitine on cerebral and hepatic energy metabolites in congenitally hyperammonemic sparse-fur mice and its role during benzoate therapy. Metabolism, Vol. 42, pp. 1039-1046

Ratnakumari, L., Qureshi, I. A., Maysinger, D., \& Butterworth R. F. (1995). Developmental deficiency of the cholinergic system in congenitally hyperammonemic spf mice: effect of acetyl-L-carnitine. J Pharmacol Exp Ther, Vol. 274, pp. 437-443

Romano, M., Vacante, M., Cristaldi, E., Colonna, V., Gargante, M.P., Cammalleri, L., \& Malaguarnera, M. (2008). L-carnitine treatment reduces steatosis in patients with chronic hepatitis C treated with alpha-interferon and ribavirin. Dig Dis Sci, Vol. 53, pp. 1114-1121

Rose, C., \& Felipo, V. (2005). Limited capacity for ammonia removal by brain in chronic liver failure: potential role of nitric oxide. Metab Brain Dis, Vol. 20, pp. 275-283

Schiodt, F. V., Atillasoy, E., \& Shakil, A. O., et al. (1999). Etiology and outcome for 295 patients with acute liver failure in the united states. Liver Transpl Surg, Vol. 5, pp. 29-34 
Shores, N.J., \& Keeffe, E.B. Is oral L-acyl-carnitine an effective therapy for hepatic encephalopathy? Review of the literature. Dig Dis Sci, Vol. 53, pp. 2330-2333

Silva, M.F., Aires, C.C., Luis, P.B., Ruiter, J.P., Ijlist, L., Duran, M., Wanders, R.J., \& Travares de Almeida, I. (2008). Valproic acid metabolism and its effects on mitochondrial fatty acid oxidation: A review. J Inherit Metab Dis, Vol. 4, [Epub ahead of print]

Siciliano, M., Annicchiarico, B. E., Lucchese, F., \& Bombardieri, G. (2006). Effects of a single, short intravenous dose of acetyl-L-carnitine on pattern-reversal visual-evoked potentials in cirrhotic patients with hepatic encephalopathy. Clin Exp Pharmacol Physiol, Vol. 33, pp. 76-80

Sima, A. A. (2007). Acetyl-L-carnitine in diabetic polyneuropathy: experimental and clinical data. CNS Drugs, Vol. 21, Suppl 1, pp. 13-23

Staub, F., Baethmann, A., Peters, J., Weigt, H., \& Kempski, O. (1990). Effects of lactacidosis on glial cell volume and viability. J Cereb Blood Flow Metab, Vol. 10, pp. 866-876

Steiber, A., Kerner, J., \& Hoppel, C. L. (2004). Carnitine: a nutritional, biosynthetic, and functional perspective. Mol. Aspects Med, Vol. 25, pp. 455-473

Sztajnkrycer, M.D. (2002). Valproic acid toxicity: overview and management. J Toxicol Clin Toxicol, Vol. 40, pp. 789-801

Therrien, G., Rose, C., Butterworth, J., \& Butterworth, R. F. (1997). Protective effect of Lcarnitine in ammonia-precipitated encephalopathy in the portacaval shunted rat. Hepatology, Vol. 25, pp. 551-556

Vielhaber, S., Feistner, H., Weis, J., Kreuder, J., Sailer, M., Schröder, J. M., \& Kunz, W. S. (2004). Primary carnitine deficiency: adult onset lipid storage myopathy with a mild clinical course. J Clin Neurosci, Vol. 11, pp. 919-924

Virmani, A., \& Binienda, Z. (2004). Role of carnitine esters in brain neuropathology. Mol Aspects Med, Vol. 25, pp. 533-549

Wadzinski, J., Franks, R., Roane, D., \& Bayard, M. (2007). Valproate-associated hyperammonemic encephalopathy. J A. Board Fam Med, Vol. 20, pp. 499-502

Waniewski, R.A., \& Martin, D.L. (1998). Preferential utilization of acetate by astrocytes is attributable to transport. J Neurosci, Vol. 18, pp. 5225-5233

Wein, C., Koch, H., Popp, B., Oehler, G., Schauder, P. (2004). Minimal hepatic encephalopathy impairs fitness to drive. Hepatology, Vol. 39, pp. 739-745

Tofteng, F., \& Larsen, F.S. (2002). Monitoring extracellular concentrations of lactate, glutamate, and glycerol by in vivo microdialysis in the brain during liver transplantation in acute liver failure. Liver Transp., Vol. 8, pp. 302-305

Zhang, H., Jia, H., Liu, J., Ao, N., Yan, B., Shen, W., Wang, X., Li, X., Luo, C., \& Liu, J. (2010). Combined R-alpha-lipoic acid and acetyl-L-carnitine exerts efficient preventative effects in a cellular model of Parkinson's disease. J Cell Mol Med, Vol. 14, pp. 215-25

Zwingmann, C., Chatauret, N., Leibfritz, D., \& Butterworth, R.F. (2003). Selective increase of brain lactate synthesis in experimental acute liver failure: results of a [H-C] nuclear magnetic resonance study. Hepatology, Vol. 37, pp. 420-428

Zwingmann, C., \& Leibfritz, D. (2003). Regulation of glial metabolism studied by ${ }^{13}$ C-NMR. NMR Biomed, Vol. 16, pp. 370-399

Zwingmann, C, \& Butterworth, R.F. (2005). An update on the role of brain glutamine synthesis and its relation to cell-specific energy metabolism in the hyperammonemic brain: Further studies using NMR spectroscopy. Neurochem Int, Vol. 143, pp. 19-30 
Zwingmann, C. (2007). Nuclear magnetic resonance studies of energy metabolism and glutamine shunt in hepatic encephalopathy and hyperammonemia. J Neurosci Res, Vol. 15, pp. 3429-3442 


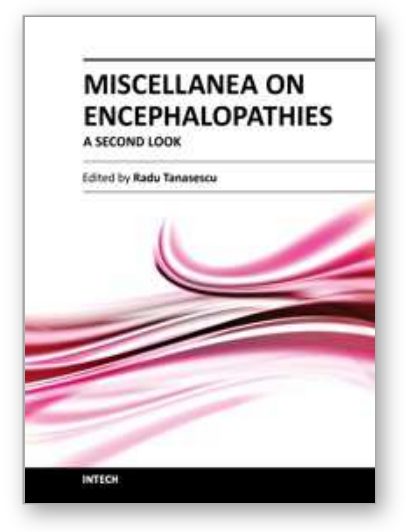

\author{
Miscellanea on Encephalopathies - A Second Look \\ Edited by Dr. Radu Tanasescu
}

ISBN 978-953-51-0558-9

Hard cover, 390 pages

Publisher InTech

Published online 25, April, 2012

Published in print edition April, 2012

The book project "Miscellanea on Encephalopathies-a second look" aims to cover some of the important aspects regarding metabolic, hypoxic, neoplasm- and drug-related encephalopathies, by transmitting valuable information filtered through the real life clinical and research experience of the authors.

\title{
How to reference
}

In order to correctly reference this scholarly work, feel free to copy and paste the following:

Jane Missler and Claudia Zwingmann (2012). L-carnitine in Hyperammonemia and Hepatic Encephalopathy, Miscellanea on Encephalopathies - A Second Look, Dr. Radu Tanasescu (Ed.), ISBN: 978-953-51-0558-9, InTech, Available from: http://www.intechopen.com/books/miscellanea-on-encephalopathies-a-secondlook/effects-of-I-carnitine-in-hyperammonemia-and-hepatic-encephalopathy

\section{INTECH}

open science | open minds

\section{InTech Europe}

University Campus STeP Ri

Slavka Krautzeka 83/A

51000 Rijeka, Croatia

Phone: +385 (51) 770447

Fax: +385 (51) 686166

www.intechopen.com

\section{InTech China}

Unit 405, Office Block, Hotel Equatorial Shanghai

No.65, Yan An Road (West), Shanghai, 200040, China 中国上海市延安西路65号上海国际贵都大饭店办公楼 405 单元

Phone: $+86-21-62489820$

Fax: $+86-21-62489821$ 
(C) 2012 The Author(s). Licensee IntechOpen. This is an open access article distributed under the terms of the Creative Commons Attribution 3.0 License, which permits unrestricted use, distribution, and reproduction in any medium, provided the original work is properly cited. 